\title{
The impact of the hot tap water load pattern in the industrial hall on the energy yield from solar collectors
}

\author{
Natalia Fidorów-Kaprawy ${ }^{1, *}$, and Edyta Dudkiewicz ${ }^{1}$ \\ ${ }^{1}$ Department of Air Conditioning, Heating, Gas Engineering and Air Protection, Faculty of \\ Environmental Engineering, Wrocław University of Science and Technology, ul. Norwida 4/6, \\ 50-373 Wrocław, Poland
}

\begin{abstract}
The systems using solar energy, popular in Poland, can be used to supply hot water for the installation used by employees of industrial halls. In manufacturing plants, employing a large number of people, the demand for hot water is practically constant throughout the year and is characterized by periodic use at the end of each work shift. Dynamics of the hot water consumption depends on the number of shifts as well as working days and holidays. Additionally the maximum hot tap water demand occurs in the whole period of installation operation. In polish climatic conditions the solar collectors' systems have the largest capacity in the summer, while in winter they need to be assisted. Beside that the supply of renewable energy is uneven and depends on weather conditions. In the paper the one-hour step analysis concerning the dependence of the load pattern of the hot tap water preparation system on the energy yield from solar collectors had been performed.
\end{abstract}

\section{Introduction}

Systems using renewable energy sources are the most promising solution to cope with increasing cost of energy production, global warming and pollutant emissions. In last years, wind and solar power generation technologies achieved high reliability and their market share increased [1]. Currently in Poland solar collectors' manufacturing sector is the best developed one among RES (renewable energy sources), producing both for export and internal market. Polish market of solar collectors for several years is at the forefront of the markets not only in Europe but in the world, both in terms of number and the surface area of annually installed solar thermal systems. According to the International Energy Agency, in 2013 Poland was in $8^{\text {th }}$ place in the world ranking of 57 leading countries in installing solar collectors and $3^{\text {rd }}$ in Europe in terms of solar installations sales with the share of $9 \%$. In year 2014 Polish market was in $4^{\text {th }}$ place in Europe in solar collector sales $[2,3]$. This has pushed investors, especially those investing in large cube halls, where the demand for energy is exceptionally high (figure 1 [4]), towards using this kind of RES. Indicators of the primary energy use indicators given in figure 1 [4] concern the level of the non-renewable

* Corresponding author: natalia.fidorow@pwr.edu.pl 
energy (contained in sources), which is necessary for covering the heat demand for heating, ventilation and hot water production.

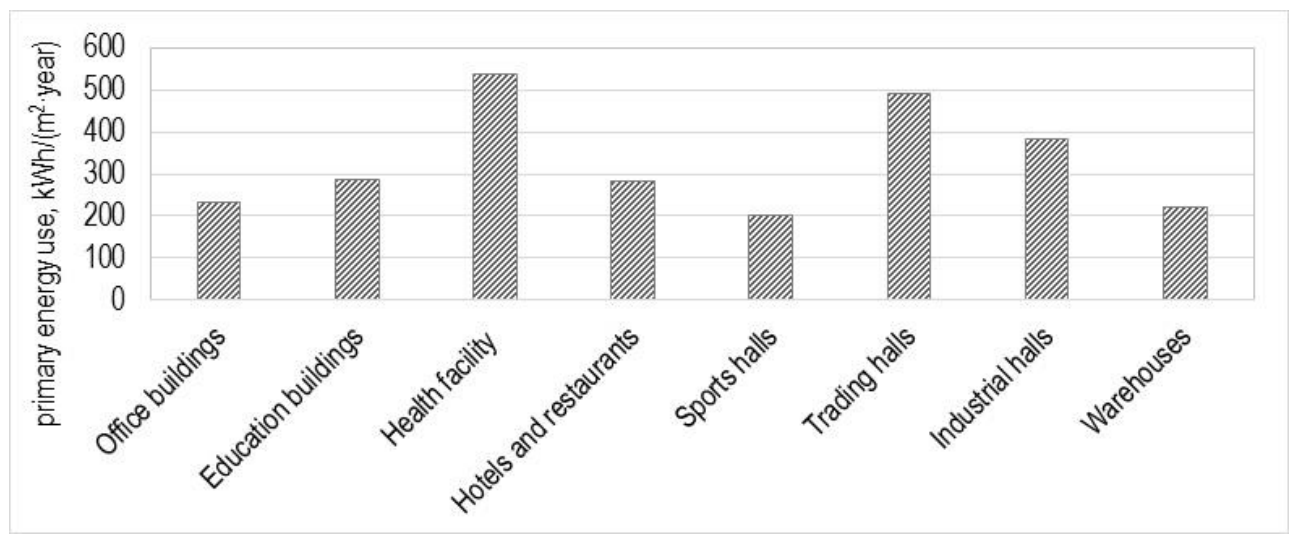

Fig. 1. The weighted average primary energy use indicator in various kinds of non-residential buildings [4].

In industrial and production halls it is possible to use solar collectors for the purposes of the hot tap water preparation, the office spaces heating and technological heat installations. Because of the high level of the technological processes' complication, the use of the heat from solar collectors for the purposes of technological installation requires the individual approach and precise analysis of the industrial process characteristics in order to ensure the integration of the solar and industrial installation. In installations of the special purpose often some new technical developments of solar collectors are required [5]. However the most frequent and popular use of solar collectors in the industrial halls is for the purposes of the hot tap water preparation for the employees. It is mostly because of the favorable ratio of the system investment costs to the obtained energy gains [3].

The supply of renewable energy is uneven and depends on weather conditions but it has been assessed, that in Polish weather conditions the hot tap water preparation installation using solar collectors may cover about $60 \%$ of the annual hot tap water demand. The amount of gained energy is higher in period from May to September and reaches up to $90 \%$ of the demand while in the remaining period it falls to about $30 \%$ [6]. Installation of the solar thermal collectors in the industrial halls unused during the summer because of the holiday season would be a mistake.

In production halls hot utility water demand has periodical peaks when showers and washbasins are used at the end of each work shift. The maximum demand for hot water occurs in whole installation working period and in practice is equal during the year. The periods of installation usage are dependent on the number of working shifts and working/holiday days during a year. Usually, the water draw-off after the first shift is larger than those after the second and third shifts owing to the larger manning during the first shift and due to some office employers working in this time. Duration of draw-off periods is generally determined and lasts for about 30 minutes. Between the main draw-off periods, there is generally low or no demand of hot water caused by sporadic use by employees from the hall and office. The daily load pattern of hot tap water in production halls is not convergent to the supply of renewable energy from solar collectors [7]. How the research $[7,8]$ shows the useful energy, and therefore the profitability, will decrease if the demand is not distributed throughout the day or focused on the end of the day. Therefore the assessment of the impact of the hot tap water load pattern in the industrial hall on the energy yield from solar collectors is important issue in terms of the energy efficiency. 
In this paper authors proposed the use of solar collectors for the purposes of the hot tap water preparation in the industrial halls with 210 employees working in one, two or three shifts. The energy yield from solar collectors was calculated basing on the one-hour step analysis. Additionally authors provided the energy gains which are the results of the calculations by f-chart method for comparison. The aim of the present work is to assess the impact of load pattern of the hot tap water for industrial hall's employees on the energy yield from solar collectors.

\section{Description of the system}

A hot tap water preparation system for 210 workers of typical production halls located in Wroclaw, Poland was assumed. This system is based on solar collectors being the basic heat source in summer (renewable heat source). For the weather conditions prevailing in Poland, the system with solar collectors has the highest capacity in summer, but in winter season it needs to be assisted by the auxiliary thermal energy source independent on weather conditions [6]. In case of analyzed system a gas boiler shall be used to cover the energy shortage from solar collectors.

A work organization in production halls from Monday to Friday (or to Saturday morning for III shift) is shown in table 1. Water consumption for bath after work completion was assumed as 50 liters per person. The temperature of cold water of $5^{\circ} \mathrm{C}$ and hot water to bath under shower of $40^{\circ} \mathrm{C}$ was assumed [9]. Hot tap water is expected to be consumed within 1 hour. The daily energy demand for the hot tap water preparation purposes is the same in each production halls, regardless on the number of work shifts.

Table 1. The work organization in the production halls.

\begin{tabular}{|c|c|c|c|c|c|}
\hline Hall no 1 & \multicolumn{2}{|c|}{ Hall no 2 } & \multicolumn{3}{c|}{ Hall no 3 } \\
\hline I shift & I shift & II shift & I shift & II shift & III shift \\
\hline 6:00-14:00 & $6: 00-14: 00$ & $14: 00-22.00$ & $6: 00-14: 00$ & $14: 00-22.00$ & $22: 00-6: 00$ \\
\hline 210 workers & 105 workers & 105 workers & 70 workers & 70 workers & 70 workers \\
\hline
\end{tabular}

The flat plate solar collectors were chosen for the system, each of surface area equal to $1.873 \mathrm{~m}^{2}$, with optical efficiency of $84.5 \%$ and heat loss coefficient equal to $4.1 \mathrm{~W} /\left(\mathrm{m}^{2} \cdot \mathrm{K}\right)$. The number of solar collectors required in the system is equal to 66 and have been selected basing on the widely used f-chart method [10]. Such number of collectors allow for their maximum use in summer months. The hot water storage unit volumetric capacity of 10000 liters was assumed and is consistent with general guidelines (close to daily water consumption and close to 75 liters per square meter of the solar collector aperture area [9]).

A gas boiler was assumed as the conventional heat source. Appropriate power, determined during analysis, allows for maintaining the minimum usable water's temperature of $45^{\circ} \mathrm{C}$ for bath [9] in the storage tank. The operation of gas boiler was assumed on the basis of time schedule as there is no need to keep the high temperature of hot tap water in storage tank continuously. During working days preset temperature of hot tap water in the storage tank is $35^{\circ} \mathrm{C}$ at two hours before the end of shift and $45^{\circ} \mathrm{C}$ at one hour before the end of shift. At all other times and during holidays, the boiler would not be turned on irrespective of the water temperature in the storage tank.

\section{Method}

The analysis focused on the energy shares calculations depending on the hot tap water load pattern. The one-hour step analysis allows taking into account the daily and weekly hot tap 
water load pattern. As the f-chart method had been used for the calculation of the needed solar collectors' aperture area, authors decided to show the energy shares calculated by this method for comparison.

While using f-chart method data on average monthly temperatures and total monthly radiation on the southern surface inclined at $45^{\circ}$ necessary to run calculations were taken from the website of the Ministry of Infrastructure and Construction [11]. Heat demand for production of hot tap water was calculated from the formula:

$$
Q_{h t w}=5 / 7 \cdot l_{d} \cdot m_{d} \cdot c_{w} \cdot\left(t_{h t w}-t_{c w}\right) \cdot 10^{-3} / 3600
$$

where: $l_{d}$ - number of days in a month $(-), m_{d}$ - daily demand for the hot tap water $(\mathrm{kg})$, $c_{w}$ - specific heat of water $(\mathrm{kJ} /(\mathrm{kg} \cdot \mathrm{K})), t_{h t w}$ - temperature in the hot water tank $\left({ }^{\circ} \mathrm{C}\right)$, $t_{c w}$ - temperature of the cold water $\left({ }^{\circ} \mathrm{C}\right)$.

The 5/7 coefficient in formula (1) was introduced to take into account the water draw-off over 5 days per week. The f-chart method does not consider periods of the maximum hot water consumption or the number of consumption periods per day.

In one-hour step analysis the data for each of the 8,760 hours of one year were analyzed. To calculate solar collectors' gains the Hottel-Whillier-Bliss equation was applied [10]:

$$
Q_{s o l}=q \cdot A_{a}=F_{R}(\tau \alpha)_{e} \cdot G \cdot A_{a}-F_{R} U_{L} \cdot\left(t_{i n}-t_{a}\right) \cdot A_{a}
$$

where: $A_{a}$ - aperture surface of the solar collector or battery of collectors $\left(\mathrm{m}^{2}\right)$, $F_{R}(\tau \alpha)_{e}$ - maximal efficiency of the solar collector $\left(t_{i n}=t_{a}\right)(-), F_{R} U_{L}$ - heat loss coefficient of the solar collector $\left(\mathrm{W} /\left(\mathrm{m}^{2} \mathrm{~K}\right)\right), G$ - intensity of solar radiation $\left(\mathrm{W} / \mathrm{m}^{2}\right), t_{\text {in }}$ - temperature of the working fluid in the solar collector inlet $\left({ }^{\circ} \mathrm{C}\right), t_{a}$ - ambient temperature $\left({ }^{\circ} \mathrm{C}\right)$.

The temperature of the liquid in a tank in each hour had been determined from energy balance equation using simple Euler integration. The equation was solved at the end of time increment:

$$
t^{\prime}{ }_{h t w}=t_{h t w}+\Delta \tau \cdot Q /\left(m \cdot c_{w}\right)
$$

where: $t^{\prime}{ }_{h t w}$ - temperature in the hot water tank before the heat delivery/withdrawal $\left({ }^{\circ} \mathrm{C}\right)$, $t_{\text {httw }}$ - temperature in the hot water tank after the heat delivery/withdrawal $\left({ }^{\circ} \mathrm{C}\right), \Delta \tau$ - method time step (3600 s), $Q$ - source thermal power or the average power transferred during one hour (W), $m$ - mass of water gathered in the hot water tank $(\mathrm{kg})$.

It was assumed that for standard operation, a circulation pump of collectors shall be turned on only when energy gains from solar collectors are greater than heat loss. The system must operate in such a way to protect the storage tank from water overheating by dissipating excess energy or the system turning off by stopping the circulation pump (emergency turning off).

The results of the one-hour step calculations showed the sources activity and enabled the determination of the sources impact (renewable and conventional one) on the water temperature in the tank. The analysis of the outcomes enabled the system elements sizing improvement and revealed the necessity of the circulation pomp's control strategy implementation to protect water in storage tank from overheating and to minimize the necessity of energy dissipation.

\section{Results and discussion}

The results of the analyses are presented below. The f-chart analysis results (not taking into account the dynamics of hot tap water load pattern) are compared to the one-hour step analysis results for three various hot tap water load patterns depending on the number of 
work shifts (table 1). In figure 2 the shares of the energy coming from the solar collectors and the gas boiler in subsequent months are shown. The 4 columns for each month from left to right concern: the energy shares calculated using f-chart method and the energy shares calculated using the one-hour step calculation method for one, two and three working shifts. The outcomes of the analysis made with one-hour step show that even in summer the gas boiler is needed for the maintenance of the demanded temperature of the water before the end of the work shift. Those situations are more frequent in case of two- and three-shift work, hence the greater share of the conventional energy from gas boiler in those cases.

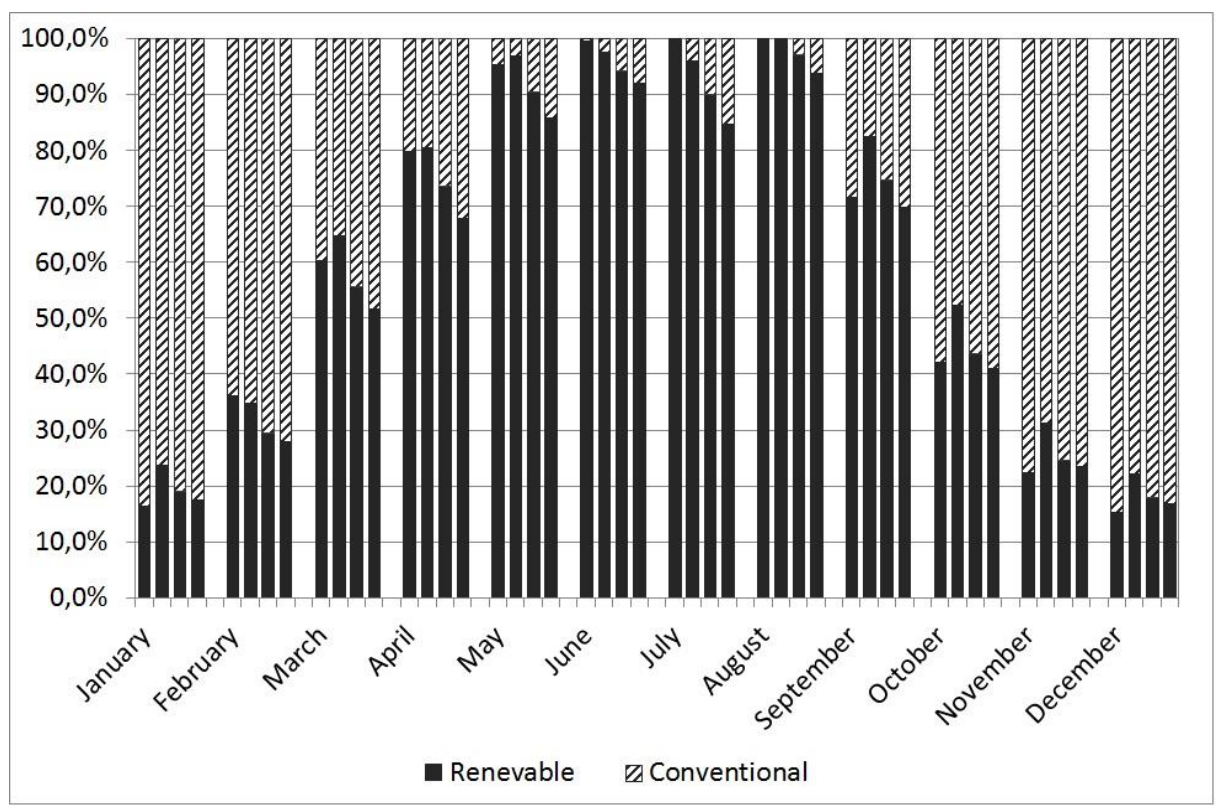

Fig. 2. The monthly energy shares from renewable and conventional sources for all analysed cases.

Table 2 summarizes average annual contributions of energy gained from the solar collectors and from the gas boiler, used to prepare hot tap water, as well as the amounts and shares of the energy that couldn't have been used and have to be dissipated. The amount of energy that couldn't have been used result from the necessity of the circulation pump turn off while the temperature in hot water tank is too high (above $90^{\circ} \mathrm{C}$ ). Those amounts of energy are not included in energy balance. Energy gained from the solar collectors is the whole amount of energy transferred from the solar collectors to the hot water tank, some of which is later dissipated because of the water in the hot water tank overheating risk. The sum of the renewable energy amount (after dissipation) with the energy gained from the gas boiler covers the $100 \%$ of the energy demand for the hot tap water preparation purposes. Additionally table 2 contains the characteristic parameters describing the installation elements (the number of solar collectors, the gas boiler required power rate, and the hot tap water tank volume) and the yearly average temperature of the water in the tank.

The number of solar collectors and resulting total active surface of the absorbers, determined using f-chart method and the volume of the hot water tank had been assumed the same for all analyzed cases. The yearly average temperatures of the water in the tank for three cases analyzed in one-hour step are the calculated values and for f-chart method is the value assumed for the calculations.

Different values of the yearly energy demand for the purposes of the hot tap water preparation for f-chart method and one-hour step method result from the different 
assumptions. In one-hour step method all non-working days (weekends and holidays) have been adequately considered and in f-chart method only the share of the working days, equal to $5 / 7$ have been assumed (formula (1)).

Table 2. The average annual shares and yields of renewable and conventional energy.

\begin{tabular}{|c|c|c|c|c|c|}
\hline & & f-chart & I shift & II shifts & III shifts \\
\hline \multicolumn{2}{|c|}{ Collectors number } & 66 & 66 & 66 & 66 \\
\hline \multicolumn{2}{|c|}{ Gas boiler power rate $[\mathrm{kW}]$} & 220 & 220 & 120 & 120 \\
\hline \multicolumn{2}{|c|}{ Hot water tank volumetric capacity [1] } & 10000 & 10000 & 10000 & 10000 \\
\hline \multicolumn{2}{|c|}{ Average temperature in hot water tank $\left[{ }^{\circ} \mathrm{C}\right]$} & 45.0 & 32.1 & 43.2 & 47.7 \\
\hline \multicolumn{2}{|c|}{ Energy demand for hot tap water purposes [kWh] } & 111515 & 108643 & 108643 & 108643 \\
\hline \multirow{2}{*}{$\begin{array}{l}\text { Energy gained from the } \\
\text { solar collectors }\end{array}$} & Amount $[\mathrm{kWh}]$ & 68938 & 75473 & 69616 & 67790 \\
\hline & Share [\%] & $61.8 \%$ & $69.5 \%$ & $64.1 \%$ & $62.3 \%$ \\
\hline \multirow{2}{*}{$\begin{array}{l}\text { Energy gained from the } \\
\text { gas boiler }\end{array}$} & Amount $[\mathrm{kWh}]$ & 42741 & 37498 & 43980 & 47560 \\
\hline & Share $[\%]$ & $38 \%$ & $34.5 \%$ & $40.5 \%$ & $43.7 \%$ \\
\hline \multirow{2}{*}{$\begin{array}{l}\text { Energy that couldn't have } \\
\text { been used }\end{array}$} & Amount [kWh] & - & 4064 & 3950 & 3451 \\
\hline & Share [\%] & - & $3.7 \%$ & $3.6 \%$ & $3.2 \%$ \\
\hline \multirow{2}{*}{$\begin{array}{l}\text { Energy dissipated via } \\
\quad \text { solar collectors }\end{array}$} & Amount [kWh] & 164 & 4327 & 4953 & 6564 \\
\hline & Share [\%] & $0.2 \%$ & $4.0 \%$ & $4.6 \%$ & $6.0 \%$ \\
\hline \multirow{2}{*}{$\begin{array}{l}\text { Renewable energy (after } \\
\text { dissipation) }\end{array}$} & Amount [kWh] & 68774 & 71146 & 64663 & 61226 \\
\hline & Share [\%] & $61.7 \%$ & $65.5 \%$ & $59.5 \%$ & $56.3 \%$ \\
\hline
\end{tabular}

As it can be seen in table 2 the shares of the particular energy balance elements differ between f-chart and one-hour step analysis as well as in one-hour step among different hot tap water loads (resulting from the number of shifts). The biggest share of the utilized solar energy equal to $65.5 \%$ occurs when one shift work is assumed. When the hot tap water load pattern characteristic for two shift work occurs, the share of the solar energy is lower and equal to $59.5 \%$; at the same time it is similar to the solar energy share obtained using f-chart method $(61.7 \%)$. The lowest renewable energy share equal to $56.3 \%$ had been obtained while analyzing the system with the tot tap water load pattern characteristic for three work shifts. After each hot tap water consumption in cases of two and three shifts work the medium temperature in the hot water tank is higher than in case of one shift work (especially during the transition period and the winter), so less energy may be transferred from solar collectors to the hot water tank.

While analyzing the system in one-hour step it can be seen that during some days the collectors deliver excess energy (especially on the weekend when there is no energy demand) so it needs to be dissipated, hence the higher value of the energy dissipated from solar collectors in this method. In general, it can be said that the f-chart method based on monthly average values do not take into account the inconsistency between the solar energy supply and hot tap water demand, which influences the energy gains form solar collectors. This may be an issue while considering the industrial objects with not untypical hot tap water load patterns.

The share of the energy that couldn't have been used is the biggest in case of one shift work $(3.7 \%)$, slightly lower for two shifts work $(3.6 \%)$ and the smallest for three shifts work (3.2\%). The results from one-hour step analysis show that the situations in which the solar energy cannot be used occur most often from June to August, during the weekends and on Mondays till 14:00, when the water accumulated in the tank has temperature above 
$90^{\circ} \mathrm{C}$. In case of three shift work the last water consumption before the weekend occurs on Saturday at 6:00 a.m., hence the temperature in the hot water tank is slightly lower at the weekend beginning in comparison to the one and two shifts work. As a result the greater amount of the solar energy may be gathered on Saturday and hence the lower share of the energy that couldn't have been used in this case.

The share of the energy dissipated via solar collectors is lowest in case of one shift work $(4.0 \%)$ and bigger for cases of work in two or three shifts $(4.6 \%$ and $6.0 \%)$. This is the result of the higher average temperature in the water tank in case of two and three shifts $\left(43.2^{\circ} \mathrm{C}\right.$ and $47.7^{\circ} \mathrm{C}$ ); the temperature equal to $65^{\circ} \mathrm{C}$, when the energy dissipation begins (if possible), is reached earlier.

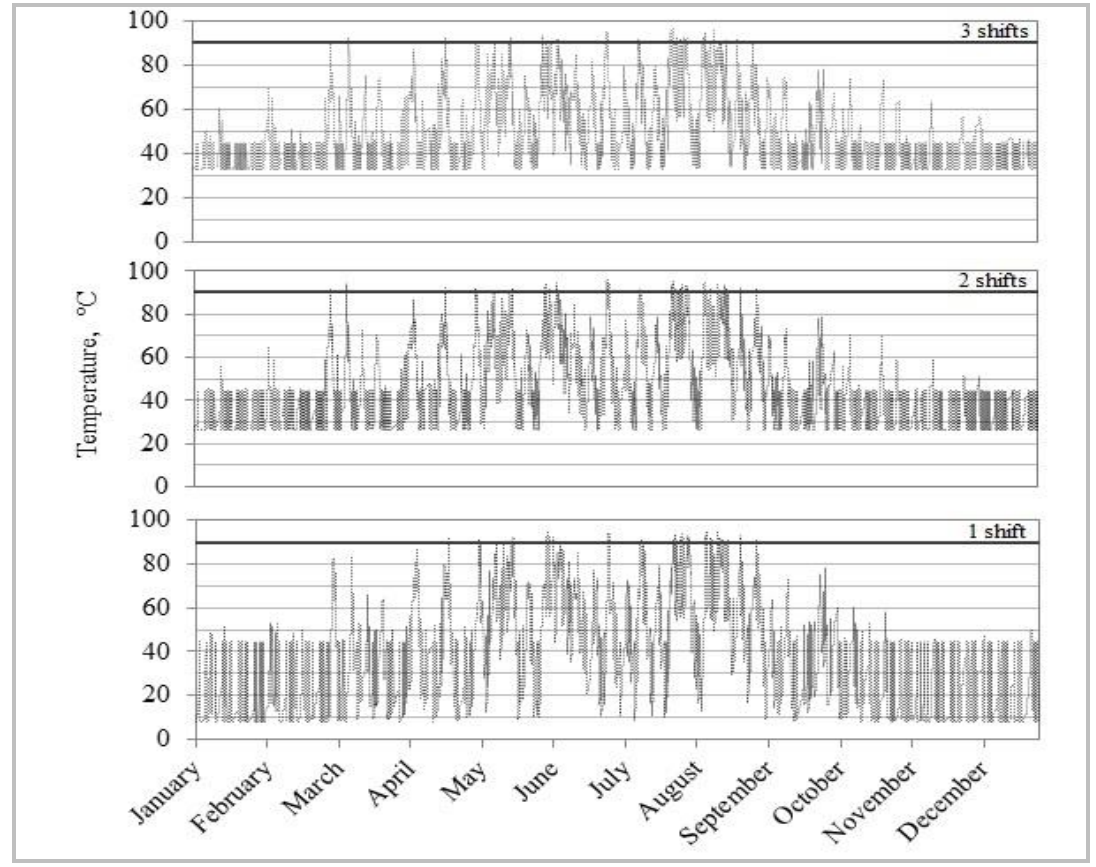

Fig. 3. Temperature in hot water tank along the year for one-, two- and three- shifts work.

In figure 3 the average temperature in the hot water tank during the year is shown. For one shift work the lowest average water temperature in the tank is $8.3^{\circ} \mathrm{C}$, for two shifts work $26.6^{\circ} \mathrm{C}$ and for three shifts work $32.8^{\circ} \mathrm{C}$. The water temperature reaching values above $90^{\circ} \mathrm{C}$ result from the step of the method. The high temperature of the water in the tank in the halls working for two and three shifts causes that, according to the system operation assumptions, the boiler have to heat up the water by 12.2 to $18.4 \mathrm{~K}$ during two hours in order to obtain the required temperature of $45^{\circ} \mathrm{C}$ before the end of the shift. This allows for selection of almost twice smaller power rate of boiler, than in the case of hall working for one shift, where the water has to be heated up by $36.7 \mathrm{~K}$ during two hours. The power rate of the gas boiler assumed while analyzing the system with f-chart method is $220 \mathrm{~kW}$ (the same as for one shift work). It should ensure the water heat up during two hours.

\section{Conclusion}

The analysis of the influence of the hot tap water load pattern on the energy yield from solar collectors carried out in the paper concerns the systems applied in industrial halls. In 
such halls the specificity of the hot tap water load pattern lies in the lack of necessity of the high level of water temperature maintenance during whole day, but only at the end of work shift. In the systems with other hot tap water consumption dynamics the influence of the hot tap water load pattern on the energy yield from solar collectors, the share of gas boiler and whole system performance may be different.

Both: higher average temperature of the water in the tank after the water consumption as well as higher average temperature during whole year cause the lower share of energy gained from solar collectors and necessity of dissipation of greater amount of energy. The highest yearly yield from the solar collectors equal to $65.5 \%$ of the annual energy demand had been reached in case of the hall with one shift work, where there is one maximal water consumption during whole day after the period of the largest operation of the sun (at 14:00). The need for the hot tap water preparation for the 210 workers in short time requires the high power rate of the gas boiler $(220 \mathrm{~kW})$, greater than in case of other hot tap water load patterns, still the share of the energy delivered by the gas boiler during whole year is in this case the lowest one $(34.5 \%)$. In the hall with one shift work the solar collectors cover $97.5 \%$ of the energy demand for hot tap water purposes in period from May to August.

The analysis of the hot tap water load pattern influence on the energy yield from solar collectors in the industrial hall showed that the magnitude of the individual water consumption incident and the fall of average water temperature in the tank after the water consumption have the great influence on the amount of energy gained from the sun. Increased number of shifts and hence lower amount of water consumed at one causes less temperature drop in the tank and the maintenance of higher yearly average temperature in the tank, which results in lower energy gain from solar collectors.

\section{References}

1. R. Cozzolino, L. Tribioli, G. Bella, Energy 106, 774-789 (2016)

2. G. Wiśniewski, A. Więcka, J. Bolesta, P. Czajka, Polish manufacturing industry for renewable energy equipment (Warszawa, 2016) (in Polish)

3. E. Dudkiewicz, Building halls (2017)

4. Financing of buildings' energy efficiency improvement in Poland BPIE (Warszawa, 2016) (in Polish)

5. J. Chodura, Rynek Instalacyjny, 12, (2011)

6. K. Pytel, A. Kłos, Scientific Papers of Rzeszów University of Technology. Civil and Environmental Engineering (Zeszyty Naukowe Politechniki Rzeszowskiej. Budownictwo i Inżynieria Środowiska), 59, 2, 645-652 (2012) (in Polish)

7. E. Dudkiewicz, N. Fidorow-Kaprawy, Energy (2017) (accepted for publication) http://dx.doi.org/10.1016/j.energy.2017.03.061

8. F.R. Mazarrón, C.J. Porras-Prieto, J.L. García, R.M. Benavente, Energy Conversion and Management 113, 16-26 (2016)

9. K. Çomaklı, U. Çakır, M. Kaya, K.Bakirci, Energy Conversion and Management 63, 112-117 (2012)

10. J.A. Duffie, W.A. Beckman, Solar Engineering of Thermal Processes (4th ed. John Wiley \& Sons, Inc., Hoboken, United States, 2013)

11. The website of the Ministry of Infrastructure and Construction: http://mib.gov.pl/2Wskazniki_emisji_wartosci_opalowe_paliwa.htm; 2016 [accessed 15.01.2015] 